\title{
Maternal and Neonatal Outcomes of Syrian Adolescent Refugees and Local Adolescent Turkish Citizens: A Comparative Study at a Tertiary Care Maternity Hospital in Türkiye
}

\author{
Ceren GOLBASI ${ }^{1}$, Tayfun VURAL ${ }^{2}$, Burak BAYRAKTAR ${ }^{2}$, Hakan GOLBASI ${ }^{2}$, Alkim Gulsah SAHINGOZ YILDIRIM² \\ Izmir, Türkiye
}

ABSTRACT

OBJECTIVE: In this study, we aim to compare the maternal and obstetric outcomes between local adolescent Turkish citizens and adolescent Syrian refugees admitted to a tertiary care center in Türkiye.

STUDY DESIGN: Between January 2014 and December 2019, a total of 57,049 births were performed in our hospital. The study included a total of 6,021 patients aged 19 years or younger pregnancy who gave birth at our hospital. Of this number, 5,164 (1,792 Syrian adolescent refugee cases and 3,372 local adolescent Turkish cases) were live singleton pregnancies. Our primary aim was to compare the maternal and obstetric outcomes between the two groups.

RESULTS: In the pregnant refugee women, the maternal age was younger $(p<0.001)$. Hemoglobin and hematocrit levels are significantly lower in Syrian pregnant women ( $p<0.001$ and $p<0.001$, respectively). Anemia was significantly higher in Syrian refugee pregnant women $(p<0.001)$. The double screening test and triple screening test were significantly lower in Syrian pregnant women $(p<0.001$ and $p<0.001$, respectively). Preterm birth rates and late preterm delivery prevalence (34-37 gestational weeks) were significantly higher in the adolescent Syrian immigrants' compared to the adolescent Turkish locals $(p<0.001$ and $p<0.001$, respectively). The average birth weight of the Syrian refugees was lower but the number of low birth weight babies was higher Turkish locals ( $p=0.010$ and $p=0.014$, respectively). The preterm birth ratio and low birth weight ratio in Syrian adolescents has decreased over the years.

CONCLUSION: Syrian adolescent refugees are particularly at risk of early pregnancy, high fertility rate, preterm birth, low birth weight, and anemia. Immigrant women should be provided with fertility, family planning, and training on behavior that protects reproductive health. Syrian pregnant women should be supported to receive services.

Keywords: Adolescent pregnancy, Antenatal care, Immigrants, Pregnancy outcome, Refugees

Gynecol Obstet Reprod Med 2022;28(2):135-143

${ }^{1}$ Department of Obstetrics and Gynecology, Tinaztepe University Faculty of Medicine Izmir, Türkiye

2 Department of Obstetrics and Gynecology, University of Health Sciences Tepecik Training and Research Hospital, Izmir, Türkiye

Address of Correspondence: Burak Bayraktar Department of Obstetrics and Gynecology University of Health Sciences Tepecik Training and Research Hospital 35180 Izmir, Türkiye drburakbayraktar@gmail.com

Submitted for Publication: 01.02.2021 Revised for Publication: 25.03.2021 Accepted for Publication: 14.04.2021 Online Published: 04.05.2021

ORCID IDs of the authors: $\quad$ CG: 0000-0002-1844-1782 TV: 0000-0002-7890-7820, BB: 0000-0001-6233-4207 $H G$ : 0000-0001-8682-5537, AGSY: 0000-0001-8707-8086

\begin{tabular}{c|c}
\hline Quick Response Code: & Access this article online \\
\cline { 2 - 2 } & $\begin{array}{c}\text { Website: www.gorm.com.tr } \\
\text { e- mail: info@gorm.com.tr }\end{array}$ \\
\cline { 2 - 2 } & DOI:10.21613/GORM.2021.1186 \\
\hline
\end{tabular}

How to cite this article: Golbasi C. Vural T. Bayraktar B. Golbasi H. Sahingoz Yildirim AG. Maternal and Neonatal Outcomes of Syrian Adolescent Refugees and Local Adolescent Turkish Citizens: A Comparative Study at a Tertiary Care Maternity Hospital in Türkiye. Gynecol Obstet Reprod Med. $2022 ; 28(2): 135-143$

\section{Introduction}

Adolescence is a period in which an individual sees an emergence of secondary sexual characters, acceleration of her/his growth, and attainment of fertility. This period refers to the transition from childhood to adulthood, and the World Health Organization (WHO) states that this period occurs between the ages of 10 and 19 years (1).

The global adolescent birth rate in 2019 was 44 per 1,000 adolescent girls aged 15-19 years (2). Pregnancies occurring in young women who have not yet reached the desired maturity levels in accordance with physical, psychological, and social aspects in all the countries of the world are a crucial public health problem. Pregnancies during this period negatively affect the health of both the mother and to-be-born baby. Anemia, prematurity, low birth weight (LBW), perinatal mortality, a need for newborn intensive care, and increased rates of interventional delivery and cesarean section are also likely to occur in adolescent pregnancies $(1,3,4)$. 
Pregnant refugee women demonstrate an increased risk of adverse pregnancy outcomes such as cesarean births, preterm births, failed induction of labor, oligohydramnios, fetal distress, and gestational diabetes (5-9). Additionally, they may face malnutrition, legal problems, as well as difficulty in receiving regular antenatal care and accessing health services $(5,10)$. The combination of these risk factors increases the risk of poor maternal and perinatal outcomes in the adolescent immigrant group.

The Syrian war started in March 2011. By May 2011, thousands of people had fled from the war to the neighboring countries, with even larger numbers displaced within Syria itself (11). Türkiye is the host to the largest number of refugees all over the world (12). In July 2019, Türkiye hosted over 3.6 million registered Syrian refugees (12). Approximately 6.1\% of this population consists of female immigrants between the ages of 12 and 17 years (12). Izmir is an industrial city located in Western Türkiye with a population of 4,320,519 people, and $3.3 \%$ of this population is Syrian refugees $(12,13)$. The health expenditures of Syrian refugees living in Izmir are covered by the Government of the Republic of Türkiye.

There are many studies in the literature on the maternal outcomes of refugees from different ethnic backgrounds and even the results of all Syrian and Turkish deliveries in our hospital were examined $(14,15)$. However, being an adolescent is already a risky pregnancy, and considering the frequency of adolescent pregnancies in Syrian refugees, we decided to plan this study. The purpose of this study is to compare the maternal and neonatal outcomes of the Syrian immigrant adolescent pregnancies between January 2014 and December 2019 in the University of Health Sciences Tepecik Training and Research Hospital. As far as we know, this study is the adolescent refugee pregnancy study with the largest sample in Türkiye.

\section{Material and Method}

We planned and conducted this retrospective study between January 2014 and December 2019 at the University of Health Sciences Tepecik Training and Research Hospital. This study included 6,021 patients aged 19 years or younger pregnant women who gave birth at our hospital. Of these patients, 5,164 (1,792 were Syrian adolescent refugee cases and 3,372 were local adolescent Turkish cases) were live singleton pregnancies. The study was approved by the University of Health Sciences Tepecik Training and Research Hospital Local Ethics Committee (approval number: 2019/7-10 date 25.04.2019). The research was conducted in accordance with the 1964 Helsinki Declaration. Informed consent is not required as it is a retrospective study.

All data were extracted from our hospital's database system and patient files. Patients with chronic disease (type I and type II diabetes mellitus, heart disease, acute-chronic infectious disease, and rheumatologic disease) and twin pregnan- cies were not included in the study. For women who were sure of their last menstruation date, gestational age was calculated with known last menstrual period (LMP). Of the patients who did not know their last menstrual period (LMP), gestational age was calculated from crown-rump length (CRL) of firsttrimester ultrasonography (US) measurements (16) (Figure 1).

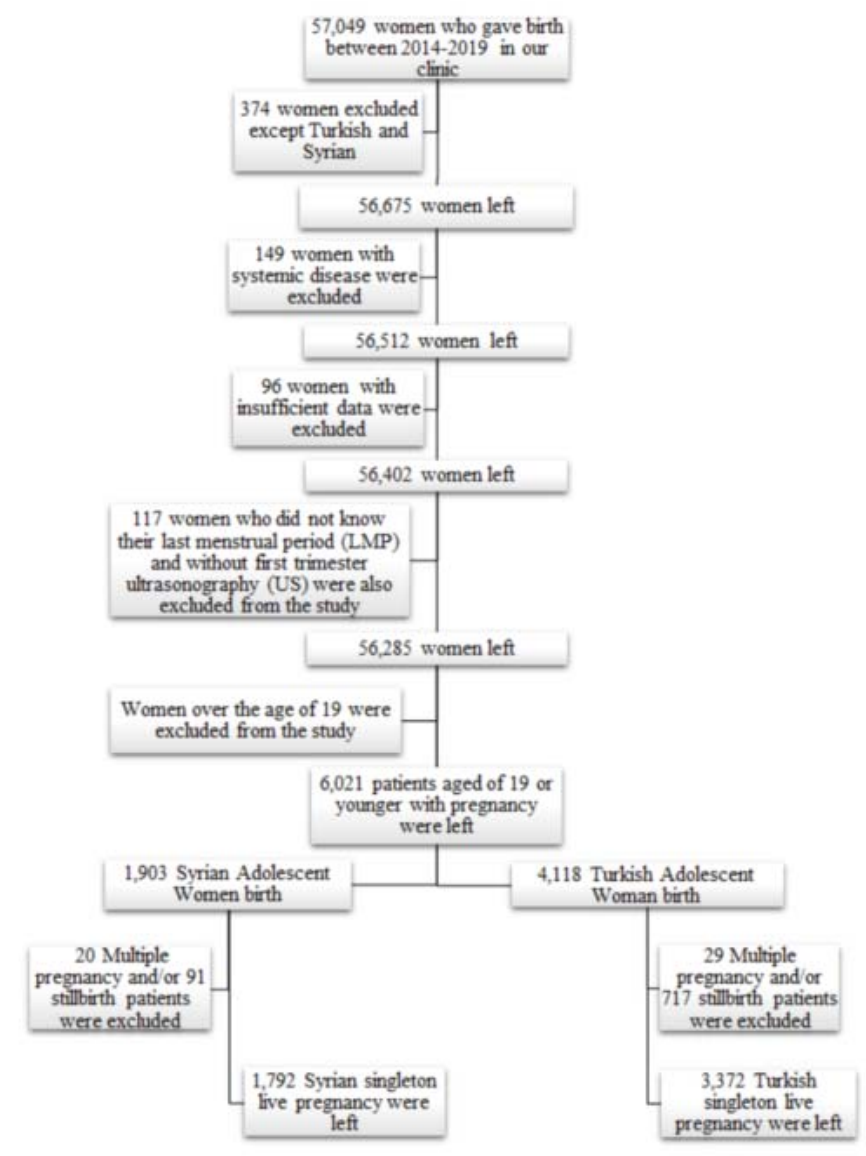

Figure 1: Pregnant women participating in the study

In classifications; delivery at $<37$ weeks as preterm birth, delivery at $\geq 42$ weeks as post-term birth, breakage of the amniotic sac before the onset of labor as premature rupture of membranes (PROM), birth weight $\geq 4000$ grams (g) as macrosomia, and birth weight $<2500 \mathrm{~g}$ as low birth weight (LBW) was used. Births after 28 weeks without signs of life were defined as stillbirth (17). Women who had at least two positive values in 100-g oral glucose tolerance test (OGTT) performed at 24-28 weeks of gestation were accepted as gestational diabetes mellitus (GDM) $(18,19)$. Hemoglobin and hematocrit levels were evaluated at admission for delivery. A double screening test in the first trimester and a triple screening test in the second trimester were used for aneuploidy screening (20).

\section{Statistical Analysis}

The results were analyzed in the Statistical Package for the Social Sciences (SPSS) version 22.0 for Windows. The normality distribution of variables was evaluated according to Kolmogorov-Smirnov $(\mathrm{n}>30)$, Shapiro-Wilk $(\mathrm{n}<30)$, and appropriate graphics. If the variables were parametric, a Student 
t-test was used. If the variables were non-parametric, the Mann-Whitney U test was used. Chi-square and Fisher exact test were used for categorical variables and the odds ratio (95\% CI) was calculated. Binary logistic regression analysis was used to determine the factors related to the cesarean section for the adolescent singleton, live pregnant women. $p<0.05$ was considered significant.

\section{Results}

We calculated "The proportion of adolescent pregnancies according to a nationality" as the proportion of the pregnant Turkish or Syrian women who were younger than 19 years and gave birth between January 2014 and December 2019 in our clinic to the whole Turkish or Syrian women who gave birth at the same time in the same clinic. In total, there were 57,049 pregnancies, and $10.5 \%$ of them were adolescent pregnancies. The number of adolescents among the pregnant Syrian refugees in our study was $1,903(22 \%)$, and this number was 4,118 (7\%) among the pregnant Turkish women. In Syrian refugees, adolescent pregnancy is significantly higher and statistically significant $(p<0.001)$.

Table I shows the characteristics, along with maternal and perinatal outcomes of the participants. The age of Turkish mothers under 19 years and immigrant mothers were found to be 18 (10-19) years and $17(10-19)$ years, respectively. In the Syrian refugee adolescent pregnant women, the maternal age was younger $(p<0.001)$. There was no statistically significant difference between the two groups with respect to multiple pregnancy rates. The rate of multiparity was higher in Syrians $(p<0.001)$. Hemoglobin and hematocrit levels were significantly lower in Syrians ( $p<0.001$ and $p<0.001$, respectively), whereas anemia was significantly higher in Syrian refugee pregnant women $(p<0.001)$. Analysis of the delivery route revealed that cesarean rates were significantly higher for Turkish women than for Syrian refugees (42.8\% vs. 25.6\%, respectively). The primary cesarean rates were higher for the Turkish adolescent population as compared to the Syrian immigrants and also statistically significant $(p<0.001)$. In Syrian refugee pregnant women, the rates of hypertensive disorders of pregnancy and PROM were significantly lower $(p=0.035$ and $p<0.001$, respectively). There was no statistical difference between the two groups with respect to stillbirth, the prevalence of fetal congenital anomaly, and the number of blood transfusions (Table I).

The most common indication for elective cesarean section in Syrian and Turkish pregnant women was a previous cesarean section, whereas the indication for emergency cesarean section was fetal distress (Table II).

Table III shows the rates of antenatal parameters. The double screening test and triple screening tests were significantly lower in Syrian pregnant women $(p<0.001$ and $p<0.001$, respectively). However, GDM screening test rates were significantly higher in Syrian pregnant women $(p=0.040)$ (Table III).

Table I: Characteristics, maternal and perinatal outcomes of pregnant Syrian and Turkish adolescents

\begin{tabular}{|c|c|c|c|}
\hline & $\begin{array}{c}\text { Syrian } \\
n=1792\end{array}$ & $\begin{array}{l}\text { Turkish } \\
n=3372\end{array}$ & $p$ \\
\hline Age (year) median (min-max) & $17(10-19)$ & $18(10-19)$ & $<0.001$ \\
\hline Parity $(n, \%)$ & & & $<0.001$ \\
\hline Nulliparous & $1289(71.9 \%)$ & $2823(83.7 \%)$ & \\
\hline Multiparous & $503(28.1 \%)$ & $549(16.3 \%)$ & \\
\hline Delivery type $(n, \%)$ & & & $<0.001$ \\
\hline Vaginal delivery & $1333(74.4 \%)$ & $1928(57.2 \%)$ & \\
\hline Cesarean section & $459(25.6 \%)$ & $1444(42.8 \%)$ & \\
\hline Cesarean Type $(n, \%)$ & & & $<0.001$ \\
\hline Primary C-section & $375(81.7 \%)$ & $1298(89.9 \%)$ & \\
\hline Repeated C-section & $84(18.3 \%)$ & $146(10.1 \%)$ & \\
\hline Multiple Pregnancy Prevalence $(n, \%)$ & $20(1.1 \%)$ & $34(1 \%)$ & 0.717 \\
\hline Stillbirth (n,\%) & $16(0.9 \%)$ & $50(1.5 \%)$ & 0.075 \\
\hline Fetal Congenital Anomaly $(n, \%)$ & $5(0.27 \%)$ & $11(0.32 \%)$ & 0.771 \\
\hline Hypertensive disorders of pregnancy $(n, \%)$ & $56(3.1 \%)$ & $147(4.3 \%)$ & 0.035 \\
\hline PROM $(n, \%)$ & $57(3.2 \%)$ & $184(5.4 \%)$ & $<0.001$ \\
\hline $\mathrm{Hb}(\mathrm{g} / \mathrm{dl})($ mean $\pm \mathrm{SD})$ & $10.8 \pm 1.5$ & $11.5 \pm 1.4$ & $<0.001$ \\
\hline Hematocrit (\%) (mean \pm SD) & $32.1 \pm 4.8$ & $34.3 \pm 5.1$ & $<0.001$ \\
\hline Anemia $(\mathrm{Hb}<11(\mathrm{~g} / \mathrm{dl}))(\mathrm{n}, \%)$ & $820(45.7 \%)$ & $987(29.2 \%)$ & $<0.001$ \\
\hline Blood Transfusion $(\mathrm{n}, \%)$ & $33(1.8 \%)$ & $36(1 \%)$ & 0.078 \\
\hline
\end{tabular}

Hb: Hemoglobin, PROM: Premature rupture of membrane, SD: Standard deviation 
Table II: Cesarean indications of pregnant women who delivered by cesarean section

\begin{tabular}{|c|c|c|c|c|c|}
\hline & \multicolumn{2}{|c|}{ Adolescent Syrians } & \multicolumn{2}{|c|}{ Adolescent Turks } & \multirow{2}{*}{$p$} \\
\hline & Number & Percent & Number & Percent & \\
\hline Fetal Distress & 119 & $6.3 \%$ & 338 & $9.9 \%$ & 0.271 \\
\hline Previous C-section & 101 & $5.7 \%$ & 161 & $4.7 \%$ & $<0.001$ \\
\hline CPD & 85 & $4.7 \%$ & 252 & $7.4 \%$ & 0.601 \\
\hline Non-progressive Labor & 34 & $1.9 \%$ & 214 & $6.3 \%$ & $<0.001$ \\
\hline Other & 120 & $7 \%$ & 479 & $14.5 \%$ & 0.004 \\
\hline Total Indications for Cesarean Delivery & 459 & $25.6 \%$ & 1444 & $42.8 \%$ & $<0.001$ \\
\hline
\end{tabular}

CPD: Cephalopelvic disproportion

Table III: Antenatal parameters of all adolescent singleton and live pregnant women participated in the study

\begin{tabular}{lrrr}
\hline & Syrian & Turkish & \\
& $\mathrm{n}=1756$ & $\mathrm{n}=3290$ & $\mathrm{p}$ \\
\hline Double screening test $(\mathrm{n}, \%)$ & $290(16.5 \%)$ & $881(26.7 \%)$ & $<0.001$ \\
Triple screening test $(\mathrm{n}, \%)$ & $210(11.9 \%)$ & $583(17.7 \%)$ & $<0.001$ \\
Gestational diabetes screening test $(\mathrm{n}, \%)$ & $229(13 \%)$ & $365(11 \%)$ & $\mathbf{0 . 0 4 0}$ \\
\hline
\end{tabular}

The prevalence of preterm birth rates and late preterm delivery (34-37 gestational weeks) was significantly higher in the adolescent Syrian immigrants as compared to the adolescent Turkish locals ( $p<0.001$ and $p<0.001$, respectively). The average birth weight of the Syrian refugees was lower but the number of LBW babies was higher in the Turkish locals $(p=0.010$ and $p=0.014$, respectively). The number of infants with macrosomia was higher in Turkish locals $(p=0.046)$. Height and head circumference were similar in the two groups. There was no statistical difference between the two groups with respect to fetal sex, post-term delivery, and APGAR score of less than 7 at the first and fifth minutes (Table IV).

Table $\mathrm{V}$ presents the risk factors associated with cesarean section, which were examined by using logistic regression analysis. Accordingly, factors such as gestational age, birth weight, macrosomia, and nationality (Turkish) increased the rates of cesarean section. However, maternal age decreased the rate of cesarean section (Table V).

Table V: Logistic regression analysis of adolescent singleton and live pregnant women in terms of cesarean section

\begin{tabular}{lcr}
\hline & OR $95 \% \mathrm{Cl}$ & \multicolumn{1}{c}{$p$} \\
\hline Maternal age & $0.91(0.86-0.97)$ & $\mathbf{0 . 0 0 2}$ \\
Gestational age & $1.05(1.01-1.08)$ & $\mathbf{0 . 0 4 9}$ \\
Birth weight & $1.02(1.01-1.03)$ & $\mathbf{0 . 0 2 4}$ \\
Macrosomia & $3.38(2.35-4.86)$ & $<0.001$ \\
Nationality (Turkish) & $2.28(2.01-2.61)$ & $<0.001$ \\
\hline
\end{tabular}

Table IV: Perinatal results of all adolescent singleton and live pregnant women who participated in the study

\begin{tabular}{|c|c|c|c|}
\hline & $\begin{array}{c}\text { Syrian } \\
n=1756\end{array}$ & $\begin{array}{l}\text { Turkish } \\
n=3290\end{array}$ & $p$ \\
\hline Gender (n,\%) & & & 0.282 \\
\hline Male prevalence & $931(53 \%)$ & $1692(51.4 \%)$ & \\
\hline Female prevalence & $825(47 \%)$ & $1598(48.6 \%)$ & \\
\hline Gestational age at birth (mean $\pm S D)$ & $38 \pm 2.3$ & $38.4 \pm 2.4$ & $<0.001$ \\
\hline Preterm Delivery Prevalence (<37 weeks) $(n, \%)$ & $377(21.5 \%)$ & $533(16.2 \%)$ & $<0.001$ \\
\hline Late Preterm Delivery Prevalence $\quad(34-37$ weeks) $(n, \%)$ & $295(16.8 \%)$ & $374(11.4 \%)$ & $<0.001$ \\
\hline Post-term Delivery Prevalence $\quad(\geq 42$ weeks) $(n, \%)$ & $11(0.6 \%)$ & $35(1.1 \%)$ & 0.119 \\
\hline Birth weight $(\mathrm{g})$ (mean $\pm S D)$ & $3043.3 \pm 515.4$ & $3062.1 \pm 591.2$ & 0.010 \\
\hline LBW $(<2500 \mathrm{~g})(\mathrm{n}, \%)$ & $193(11 \%)$ & $441(13.4 \%)$ & 0.014 \\
\hline Head Circumference $(\mathrm{cm})(\operatorname{mean} \pm S D)$ & $34 \pm 2$ & $34 \pm 2$ & 0.820 \\
\hline Height $(\mathrm{cm})($ mean $\pm S D)$ & $49.1 \pm 2.4$ & $49.1 \pm 11.4$ & 0.279 \\
\hline Macrosomia ( $\geq 4000 \mathrm{~g})(\mathrm{n}, \%)$ & $45(2.6 \%)$ & $118(3.6 \%)$ & 0.046 \\
\hline APGAR Score $<7$ at 1 st minute $(n, \%)$ & $133(7.6 \%)$ & $312(9.5 \%)$ & 0.130 \\
\hline APGAR Score $<7$ at 5 th minute $(n, \%)$ & $45(2.6 \%)$ & $66(2 \%)$ & 0.200 \\
\hline
\end{tabular}


The preterm birth ratio in Syrian adolescents has decreased over the years; it was $26.3 \%$ in 2014 and $19.5 \%$ in 2019 . The LBW ratio in Syrian adolescents has decreased over the years; it was $21.1 \%$ in 2014 and $12.4 \%$ in 2019 (Figure 2). Figure 3 shows the preterm birth ratio and LBW ratio results of Turkish adolescent pregnant women (Figure 3).

Syrian Adolescent Refugees Result:
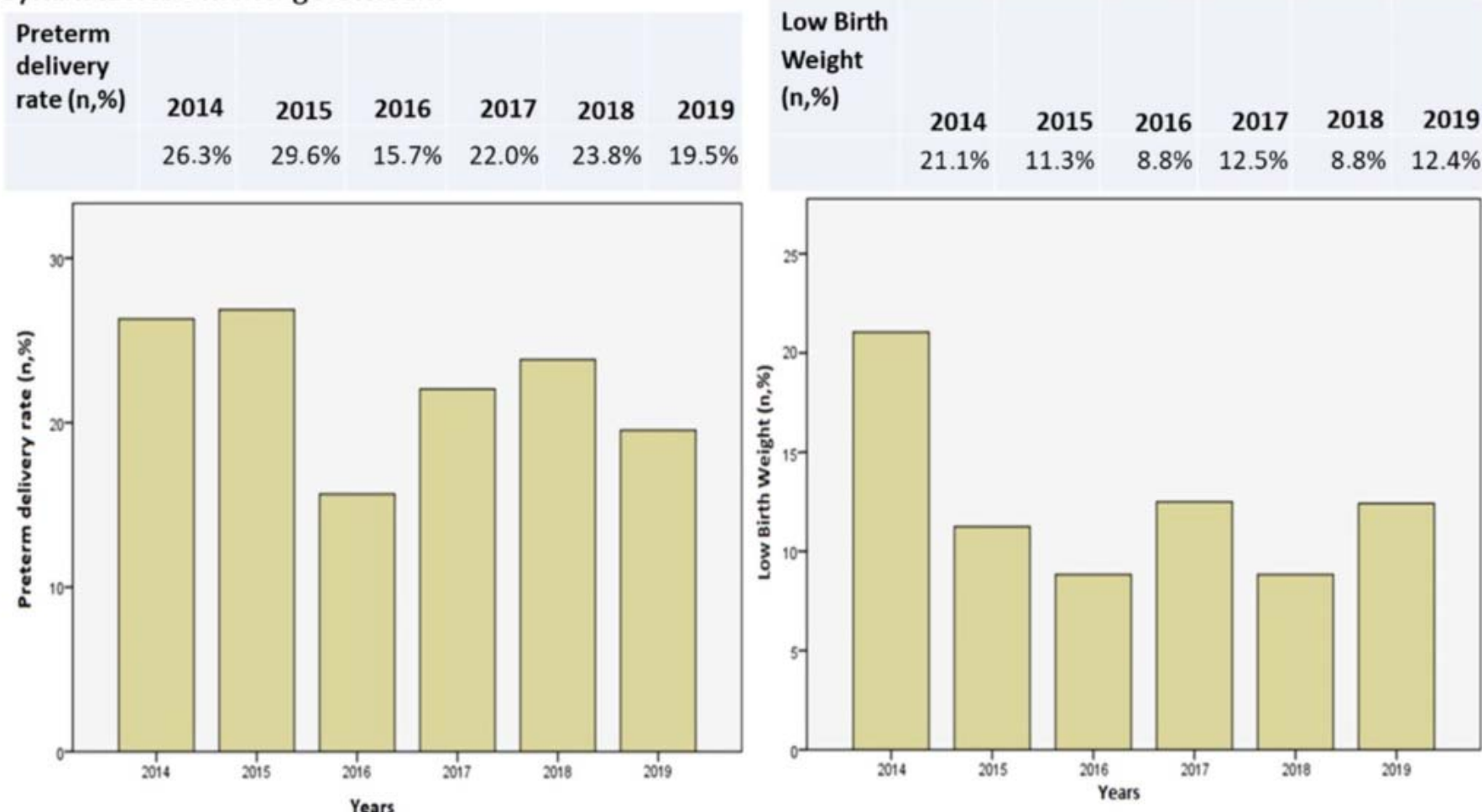

Figure 2: The incidence of preterm delivery rate and low birth weight (LBW) rate by Syrian adolescent refugees

Local TurkishAdolescent Result:
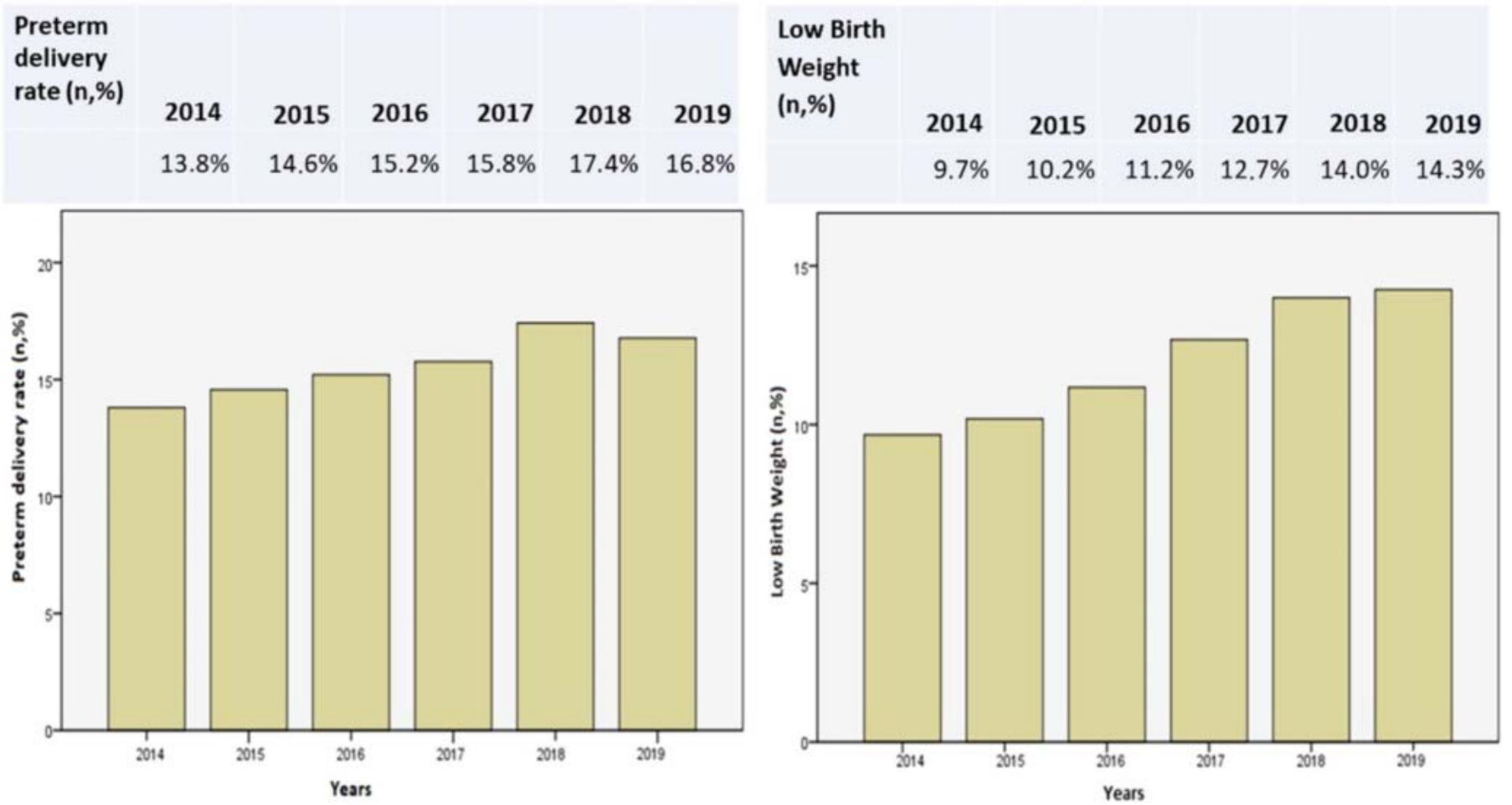

Figure 3: The incidence of preterm delivery rate and low birth weight (LBW) rate by local Turkish adolescent 


\section{Discussion}

Since 2011, Türkiye has come under a huge immigration wave because of the war that broke out in Syria between its government and the rebel forces (21). According to the United Nations Refugee Agency, the total number of immigration to Türkiye has reached 3,629,820 in July 2019 (12). Izmir has a population of 4,320,519 people, and the number of registered Syrian immigrants in the province of Izmir, where our hospital is located, has reached $3.3 \%$ of the population residing in the province $(12,13)$. The Syrian civil war caused the displacement of millions of Syrians, and the number of Syrian refugees giving birth in Türkiye is increasing over time.

Health services for Syrians under temporary protection started when they first entered Türkiye's Hatay province on April 29, 2011. The Center for Middle Eastern Strategic Studies (ORSAM) report titled "The Effects of Syrian Refugees in Türkiye 2015" states that Syrians received between $30 \%$ and $40 \%$ of total services in the state hospitals located in the border provinces. For this reason, there was a capacity problem in the state hospitals located in the border provinces $(22,23)$. Not only refugees in Türkiye, but also people living in Syria who were injured in clashes are being treated in these hospitals, and there was a capacity problem in terms of both physical conditions and health care workers. Beginning from 2011, when Syrians began to enter our country, to December $11,2017,31,449,800$ examinations were conducted, 1,326,849 patients were hospitalized and treated, 1,112,058 Syrian patients underwent surgery, 276,158 Syrian babies were born in hospitals, and 3,215,128 doses of vaccines were administered to Syrian babies and children in accordance with the vaccination schedule (24). This dramatic increase in the immigrant population has negatively affected healthcare services. All the healthcare services are provided free of charge to the Syrian refugees. Iron and multivitamin supplementation is also free of charge to pregnant women. During pregnancy, Syrian refugee pregnant women should make antenatal visits at least four times to their family physicians.

Health services offered to pregnant women are among the most important elements of health. In this study, we compared the antenatal, obstetric, and neonatal outcomes of Syrian and Turkish adolescent pregnant women. Between January 2014 and December 2019, there were 57,049 births in our hospital. $10.5 \%$ of these births were adolescent births. High-risk pregnant women are specially referred to our hospital in our daily practice. While the number of adolescent pregnant Syrian refugees in our study was $1,903(22 \%)$, this number was 4,118 (7\%) for the pregnant Turks. Syrian refugees constitute an important part of our total patient population.

In our study, we found that the average age was lower and the adolescent birth rate was higher in the refugee pregnant women ( $p<0.001$ and $p<0.001$, respectively). The mean parity number was also significantly higher in the refugee pregnant women $(p<0.001)$. Women's fertility is associated with many factors such as ethnicity, age, education, marriage, and socioeconomic status $(25,26)$. The cause is often hidden in the death of one of the parents. The death of one of the parents leaves the family in grave condition. Families try to marry their daughters to ease their economic conditions (27).

The rate of preterm birth in Syrian adolescent refugee pregnant women is significantly higher $(p<0.001)$. Problems such as inadequate antenatal care, malnutrition, insufficient iron support, social isolation, posttraumatic stress syndrome, unemployment, fear of death, and lack of education in Syrian refugee pregnant women may lead to negative pregnancy outcomes (28-32). Considering the years, while preterm birth was $26.3 \%$ in Syrian adolescents in 2014, it was $19.5 \%$ in 2019 and decreased over the years. It can be assumed that access to health services, which was much worse in the first years of the war, has slightly improved over time. The mean birth weight in Syrian refugee adolescent pregnant women was significantly lower $(p<0.001)$. This may be due to the high number of preterm births. Also, LBW was higher in Turkish newborns $(p<0.001)$. This phenomenon can be explained by the fact that the prevalence of late preterm delivery (34-37 gestational weeks) was higher in Syrians $(p<0.001)$. The incidence of LBW in Turkish adolescents was $9.7 \%$ in 2014 and $14.3 \%$ in 2019. This situation parallels the slight increase in preterm delivery rates.

In the Turkish adolescent group, gestational hypertension and PROM were significantly higher than the Syrian adolescent population $(p<0.001$ and $p<0.001$, respectively). Some infectious factors (urinary tract or vagina), maternal malnutrition, low socioeconomic status, smoking, and so on are among the possible causes of premature rupture of membranes (33). While the incidence of preeclampsia and eclampsia worldwide varies between $5-26 \%$, little is known about the varying rates in immigrant and local women (34). Increased awareness with the improvement of antenatal care improves the diagnosis of hypertension in pregnancy $(35,36)$. Moreover, ethnicity is also a risk factor (36).

In our study, the cesarean delivery rates were significantly higher in Turkish pregnant women $(p<0.001)$. Also, the primary cesarean section was significantly higher in the Turkish citizens in our study $(p<0.001)$. Similarly, various researchers have also reported that the rate of deliveries by cesarean section was lower in refugees $(29,37,38)$.

In our study, similar to some previous studies, hemoglobin and hematocrit levels in pregnant women were significantly lower and anemia rates were significantly higher in pregnant women ( $p<0.001, p<0.001$, and $p<0.001$, respectively). This condition may be due to malnutrition and poor antenatal care $(22,29,39)$.

Antenatal care is a clinical procedure for the healthy out- 
come of pregnancy for mother and baby. In our country, the Ministry of Health is obliged to detect pregnancy until the 14th week and make the first follow-up. The pregnancy is to be followed at least four times until delivery. The number of follow-ups should be increased for those who are found to be at a risk for themselves or their babies. In our study, the rates of double and triple screening tests were significantly lower in the refugee pregnant women $(p<0.001$ and $p<0.001$, respectively). In a study conducted in Lebanon, the follow-ups of Syrian refugees cannot be done regularly (38). Demirci et al. reported that the antenatal follow-up of refugees was insufficient (29). Reese-Masterson et al. reported that only 51\% of Syrian refugees had antenatal care with poor perinatal outcomes (39). Language differences, social isolation, and cultural differences are some of the reasons for inadequate antenatal care $(5,10)$. Inadequate antenatal care increases maternal mortality and morbidity $(38,39)$.

We found the rate of having a GDM screening test was higher in Syrians $(p=0.040)$. However, we could not compare the GDM prevalence because most of the Syrian and Turkish adolescent patients did not receive GDM screening tests. The following reason can be attributed to this observation: recently, some Turkish pregnant women think that the glucose tolerance test will harm the fetus, which led to their refusal to undergo screening tests (40).

The prevalence of APGAR score of less than 7 at the first and fifth minute was similar between the groups. This may be because the late preterm delivery rates of the Syrians are higher despite all the bad conditions. Also, the results are similar to those of Turkay et al.(41).

The logistic regression analysis performed in the whole adolescent group revealed that gestational age, birth weight, macrosomia, and being an adolescent Turkish citizen significantly increased the cesarean rates. Moreover, maternal age has decreased the cesarean rates.

The limitations of our study: Retrospective study is the most important limitation of our study and we could not access some data because it was. The data in our hospital, which is a tertiary center, may not reflect the whole Syrian group. For this reason, multicenter prospective studies are needed.

The strengths of our study: Our study is a large sample study that examines the maternal-obstetric results of pregnant immigrant adolescents and pregnant local adolescents.

\section{Conclusion}

There are significant differences between Turkish and refugee adolescent pregnant women. Antenatal follow-up of refugee pregnant women is not enough. Syrian refugees are particularly at risk for adolescent early pregnancy, high fertility rate, preterm birth, LBW, and anemia. Immigrant women should be provided with fertility, family planning, and training on behavior that protects reproductive health. Syrian pregnant women should be supported to receive services. It would be useful to have an interpreter in clinics.

\section{Acknowledgment: None}

Competing interests: The authors declare that they have no competing interests.

Funding: The authors received no funding for this work.

Ethics approval and consent to participate: Informed consent is not required as it is a retrospective study. The study was reviewed and approved by the ethics committee of the University of Health Sciences Tepecik Training and Research Hospital (approval number: 2019/7-10 date 25.04.2019). All procedures were performed according to the Declaration of Helsinki.

Availability of data and materials: The data supporting this study is available through the corresponding author upon reasonable request.

Authors' contributions: CG conducted the population study, analyzed and interpreted the data, and drafted the manuscript. $B B$ participated in data analysis, interpretation, and draft revision. TV and HG participated in data collection and result interpretation. TV, HG, AGSY assisted with data collection and analysis. All authors read and approved the final manuscript.

\section{References}

1. WHO, Adolescent Pregnancy Issues in Adolescent Health and Development, 2005. Department of Child and Adolescent Health and Development, Geneva. Available at: https://apps.who.int/iris/bitstream/handle/10665/4290 3/9241591455_eng.pdf;jsessionid=A8E095ED64B74671 D7AC361DC8A41F05? sequence $=1$

2. WHO, Adolescent birth rate, situation. Available at: https://www.who.int/gho/maternal_health/reproductive_h ealth/adolescent_fertility/en/ Accessed 29 Mar 2019.

3. Stevens-Simon C, McAnarney ER. Adolescent pregnancy. Gestational weight gain and maternal and infant outcomes. Am J Dis Child. 1992;146(11):1359-64. Doi: 10. 1001/archpedi.1992.02160230117031.

4. Hoekelman R. Teenage pregnancy-one of our nation's most challenging dilemmas. Pediatr Ann. 1993;22(2):812. Doi: 10.3928/0090-4481-19930201-04

5. Winn A, Hetherington E, Tough S. Caring for pregnant refugee women in a turbulent policy landscape: perspectives of health care professionals in Calgary, Alberta. Int J Equity Health. 2018;17(1):91 Doi: 10.1186/s12939-0180801-5.

6. Johnson EB, Reed SD, Hitti J, Batra M. Increased risk of adverse pregnancy outcome among Somali immigrants in Washington state. Am J Obstet Gynecol. 2005;193(2): 475-82. Doi: 10.1016/j.ajog.2004.12.003.

7. Wanigaratne S, Cole DC, Bassil K, Hyman I, Moineddin 
$\mathrm{R}$, Urquia ML. The influence of refugee status and secondary migration on preterm birth. J Epidemiol Community Health. 2016;70(6):622-8. Doi: 10.1136/jech2015-206529.

8. Gibson-Helm M, Boyle J, Cheng IH, East C, Knight M, Teede $\mathrm{H}$. Maternal health and pregnancy outcomes among women of refugee background from Asian countries. Int $\mathrm{J}$ Gynaecol Obstet. 2015;129(2):146-51. Doi: 10.1016/j. ijgo.2014.10.036.

9. Merry L, Small R, Blondel B, Gagnon AJ. International migration and caesarean birth: a systematic review and meta-analysis. BMC Pregnancy Childbirth. 2013;13:27. Doi: 10.1186/1471-2393-13-27.

10. Erenel H, Aydogan Mathyk B, Sal V, Ayhan I, Karatas S, Koc Bebek A. Clinical characteristics and pregnancy outcomes of Syrian refugees: a case-control study in a tertiary care hospital in Istanbul, Türkiye. Arch Gynecol Obstet. 2017;295(1):45-50. Doi: 10.1007/s00404-016-4188-5.

11. The UN Refugee Agency Syria Emergency. Available at: http://www.unhcr.org/syria-emergency.html Accessed 10 Mar 2018

12. The UN Refugee Agency, 2019. Inter-agency Information Sharing Portal Available at http://data.unhcr.org/syrianrefugees/country.php?id=224 Accessed 10 Apr 2019

13. Turkish Statistical Institute, 2019. Available at: http:// www.tusik.gov.tr/Start.do Accessed 10 Apr 2019

14. Kanmaz AG, İnan AH, Beyan E, Özgür S, Budak A. Obstetric outcomes of Syrian refugees and Turkish citizens. Arch Iran Med. 2019;22(9):482-88. PMID: 31679368 .

15. Vural T, Gölbaşı C, Bayraktar B, Gölbaşı H, Yıldırım AGŞ. Are Syrian refugees at high risk for adverse pregnancy outcomes? A comparison study in a tertiary center in Türkiye. J Obstet Gynaecol Res. 2021;47(4):13531361. Doi: $10.1111 /$ jog. 14673 .

16. Bayraktar B, Vural T, Gölbaşı C, Gölbaşı H, Bayraktar MG. Effect of Co-twin Fetal Sex on Fetal Anthropometry and Birth Time in Twin Pregnancies. J Obstet Gynaecol Can. 2021:S1701-2163(21)00230-9. Doi: 10.1016/j.jogc. 2021.02.113.

17. World Health Organization. Maternal, Newborn, Child and Adolescent Health: Stillbirth. Available at: http:// www.who.int/maternal_child_adolescent/epidemiology/st illbirth/en/. Accessed 25 Apr 2018

18. Carpenter MW, Coustan DR. Criteria for screening tests for gestational diabetes. Am J Obstet Gynecol. 1982; 144(7):768-73. Doi: 10.1016/0002-9378(82)90349-0.

19. Bayraktar B, Balıkoğlu M, Kanmaz AG. Pregnancy outcomes of women with hypoglycemia in the oral glucose tolerance test. J Gynecol Obstet Hum Reprod. 2020;49 (4):101703. Doi: 10.1016/j.jogoh.2020.101703.

20. Bonacquisto L. Antenatal screening-the first and second trimester. Aust Fam Physician. 2011;40(10):785-7.
PMID: 22003480.

21. Republic of Türkiye Prime Ministry Disaster and Emergency Management Presidency, 2014. Syrian refugees in Türkiye; field survey results. Available at: http://www.afad.gov.tr Accessed 15 Apr 2019

22. Ozel S, Yaman S, Kansu-Celik H, Hancerliogullari N, Balci N, Engin-Ustun Y. Obstetric outcomes among Syrian refugees: A Comparative Study at a Tertiary Care Maternity Hospital in Türkiye. Rev Bras Ginecol Obstet. 2018;40(11):673-9. Doi: 10.1055/s-0038-1673427.

23. The Center for Middle Eastern Strategic Studies, 2015. The Effects of Syrian Refugees on Türkiye 2015. Available at: https://orsam.org.tr/en/home-page/ Accessed 15 Apr 2019

24. Republic of Türkiye Prime Ministry Disaster and Emergency Management Presidency, 2017. Türkiye Response to Syria Crisis. Available at: http://www. afad.gov.tr Accessed 15 Apr 2019

25. Cetorelli V. The effect on fertility of the 2003-2011 war in Iraq. Popul Dev Rev. 2014;40(4):581-604. Doi: 10.1111/ j.1728-4457.2014.00001.x.

26. Beiser $M$. The health of immigrants and refugees in Canada. Can J Public Health. 2005;96 Suppl 2(Suppl 2): S30-44. Doi: 10.1007/BF03403701.

27. Population Reference Bureau (PRB), 2013. Child marriage in the Arab Region. Available at: https://www. prb. org Accessed 18 Apr 2019

28. Sagili H, Pramya N, Prabhu K, Mascarenhas M, Reddi Rani P. Are teenage pregnancies at high risk? A comparison study in a developing country. Arch Gynecol Obstet. 2012;285(3):573-7. Doi: 10.1007/s00404-011-1987-6.

29. Demirci H, Yildirim Topak N, Ocakoglu G, Karakulak Gomleksiz M, Ustunyurt E, Ulku Turker A. Birth characteristics of Syrian refugees and Turkish citizens in Türkiye in 2015. Int J Gynaecol Obstet. 2017;137(1):63-6. Doi: 10.1002/ijgo.12088.

30. Ganchimeg T, Ota E, Morisaki N, Laopaiboon M, Lumbiganon $\mathrm{P}$, Zhang J, et al. Pregnancy and childbirth outcomes among adolescent mothers: a World Health Organization multicountry study. BJOG. 2014;121 Suppl 1:40-8. Doi: 10.1111/1471-0528.12630.

31. Seng JS, Oakley DJ, Sampselle CM, Killion C, GrahamBermann S, Liberzon I. Posttraumatic stress disorder and pregnancy complications. Obstet Gynecol. 2001;97(1):1722. Doi: 10.1016/s0029-7844(00)01097-8.

32. Rogal SS, Poschman K, Belanger K, Howell HB, Smith $\mathrm{MV}$, Medina J, et al. Effects of posttraumatic stress disorder on pregnancy outcomes. J Affect Disord. 2007;102(13):137-43. Doi: 10.1016/j.jad.2007.01.003.

33. Alger LS, Pupkin MJ. Etiology of preterm premature rupture of the membranes. Clin Obstet Gynecol. 1986;29 (4):758-70. Doi: 10.1097/00003081-198612000-00005. 
34. van den Akker T, van Roosmalen J. Maternal mortality and severe morbidity in a migration perspective. Best Pract Res Clin Obstet Gynaecol. 2016;32:26-38. Doi: 10.1016/j.bpobgyn.2015.08.016.

35. Muti M, Tshimanga M, Notion GT, Bangure D, Chonzi P. Prevalence of pregnancy induced hypertension and pregnancy outcomes among women seeking maternity services in Harare, Zimbabwe. BMC Cardiovasc Disord. 2015;15:111. Doi: 10.1186/s12872-015-0110-5.

36. ACOG Practice Bulletin No. 202: Gestational Hypertension and Preeclampsia. Obstet Gynecol. 2019; 133(1):1. Doi: 10.1097/AOG.0000000000003018.

37. Büyüktiryaki M, Canpolat FE, Alyamaç Dizdar E, Okur N, Kadığlu Şimşek G. Neonatal outcomes of Syrian refugees delivered in a tertiary hospital in Ankara, Türkiye. Confl Health. 2015;9:38. Doi: 10.1186/s13031015-0066-1. Erratum in: Confl Health. 2016;10:23.

38. Huster KM, Patterson N, Schilperoord M, Spiegel P. Cesarean sections among Syrian refugees in Lebanon from December 2012/January 2013 to June 2013: probable causes and recommendations. Yale J Biol Med. 2014; 87(3):269-88. PMID: 25191143.

39. Reese Masterson A, Usta J, Gupta J, Ettinger AS. Assessment of reproductive health and violence against women among displaced Syrians in Lebanon. BMC Womens Health. 2014;14(1):25. Doi: 10.1186/14726874-14-25.

40. Hocaoglu M, Turgut A, Guzin K, Yardimci OD, Gunay T, Bor ED, et al. Why some pregnant women refuse glucose challenge test? Turkish pregnant women's perspectives for gestational diabetes mellitus screening. North Clin Istanb. 2018;6(1):7-12. Doi: 10.14744/nci.2018.37167.

41. Turkay Ü, Aydın Ü, Çalışkan E, Salıcı M, Terzi H, Astepe B. Comparison of the pregnancy results between adolescent Syrian refugees and local adolescent Turkish citizens who gave birth in our clinic. J Matern Fetal Neonatal Med. 2020;33(8):1353-1358. Doi: 10.1080/14767058.2018. 1519016 . 